\title{
Kidney Cancer pT0 TNM Finding v8
}

National Cancer Institute

\section{Source}

National Cancer Institute. Kidney Cancer pT O TNM Finding v8. NCI Thesaurus. Code C140284.

Kidney cancer with no evidence of primary tumor. (from AJCC 8th Ed.) 